\title{
PENGARUH KESADARAN WAJIB PAJAK, SANKSI PAJAK DAN SISTEM SAMSAT DRIVE THRU TERHADAP KEPATUHAN WAJIB PAJAK DALAM MEMBAYAR PAJAK KENDARAAN BERMOTOR PADA KANTOR SAMSAT BANDAR LAMPUNG
}

\author{
Dwi Anggraeni Saputri \\ Program Studi Akuntansi Fakultas Bisnis Universitas Mitra Indonesia \\ email.dwianggraenisaputri@umitra.ac.id \\ Nur Anisa \\ Program Studi Akuntansi Fakultas Bisnis Universitas Mitra Indonesia \\ email.Anisacahaya017@gmail.com
}

\begin{abstract}
This study aims to determine the effect of taxpayer awareness, tax sanctions, and samsat drive thru system on taxpayer compliance in paying motor vebicle tax at the Bandar Lampung Samsat Office. The method of analysis uses multiple linear regression. The population was taken from motorized taxpayers who were registered at the Bandar Lampung Samsat Office. The sample used in this study was 100 respondents and the sampling technique used random sampling. The variables in this study are independent variables, namely taxpayer awareness $\left(X_{1}\right)$, tax sanctions $\left(X_{2}\right)$ and samsat drive thru system $\left(X_{3}\right)$, while the dependent variable is taxpayer compliance $(Y)$. data were analyzed using SPSS. The results showed that the awareness of taxpayers, tax sanctions, and samsat drive thru systems simultaneously had a positive and significant effect on taxpayer compliance in paying motor vehicle tax at the Bandar Lampung Samsat Office.
\end{abstract}

Keywords: taxpayer awareness, tax sanctions, samsat drive thru system, taxpayer compliance

\begin{abstract}
Abstrak
Penelitian ini bertujuan untuk mengetahui pengaruh kesadaran wajib pajak, sanksi pajak, dan sistem samsat drive thru terhadap kepatuhan wajib pajak dalam membayar pajak kendaraan bermotor di Kantor Samsat Bandar Lampung. Metode analisis menggunakan regresi linier berganda. Populasi diambil dari wajib pajak bermotor yang terdaftar di Kantor Samsat Bandar Lampung. Sampel yang digunakan dalam penelitian ini adalah 100 responden dan teknik pengambilan sampel menggunakan random sampling. Variabel dalam penelitian ini adalah variabel bebas, yaitu kesadaran wajib pajak (X1), sanksi pajak (X2) dan samsat drive thru system (X3), sedangkan variabel terikatnya adalah kepatuhan wajib pajak (Y). data dianalisis menggunakan SPSS. Hasil penelitian menunjukkan bahwa kesadaran wajib pajak, sanksi pajak, dan samsat drive melalui sistem secara simultan berpengaruh positif dan signifikan
\end{abstract}


terhadap kepatuhan wajib pajak dalam membayar pajak kendaraan bermotor di Kantor Samsat Bandar Lampung.

Kata kunci : kesadaran wajib pajak, sanksi pajak, samsat drive melalui sistem, kepatuhan wajib pajak

\section{PENDAHULUAN}

Perkembangan kendaraan bermotor yang setiap tahunnya selalu bertambah, tentunya dapat dimanfaatkan oleh Kantor Samsat Bandar Lampung untuk melakukan pemungutan pajak kepada pemilik kendaraan bermotor yang terdaptar pada Kantor samsat Bandar Lampung untuk meningkatan sumber pendapatan asli daerah agar dapat memaksimalkan kemampuan daerah dan mencerminkan keadaan dan mencerminkan kemampuan ekonomi yang baik dan stabil, namun pada kenyataannya kepatuhan wajib pajak masih sangat rendah, dalam membayar pajak kendaraan bermotor yang merupakan kewajiban mereka untuk membayarnya dapat dilihat dari jumlah tunggakan dan denda PKB di Kantor Samsat Bandar Lampung. Berdasarkan yang diperoleh dari Kantor Samsat Kota Bandar Lampung tahun 2017.

Tabel 1:

Data Penunggakan Wajib Pajak Kendaraaan Bermotor

Di Kantor Samsat Bandar Lampung

Tahun 2017

\begin{tabular}{|c|c|c|}
\hline TAHUN & $\begin{array}{c}\text { JUMLAH WAJIB PAJAK } \\
\text { YANG MENUNGGAK PKB } \\
\text { (ORANG) }\end{array}$ & $\begin{array}{c}\text { JUMLAH TUNGGAKAN } \\
\text { (RUPIAH) }\end{array}$ \\
\hline 2017 & 101.472 & 15.224 .286 .213 \\
\hline
\end{tabular}

Sumber : Kantor Samsat Bandar Lampung (2020)

Berdasarkan pada tabel 1.2 dapat diketahui bahwa pada tahun 2017 terjadi penunggakan pembayaran pajak kendaraaan bermotor sebanyak 101.472 orang wajib pajak dengan jumlah tunggakan Rp.15.224.286.213. Berdasarkan latar belakang peneltian ini, penulis tertarik untuk mengambil judul penelitian "Pengaruh Kesadaran Wajib Pajak, Sanksi Pajak, Dan Sistem Samsat Drive Thru Terhadap Kepatuhan Wajib Pajak Dalam Membayar Pajak Kendaraan Bermotor Pada Kantor Samsat Bandar Lampung"

\section{Tinjauan Pustaka}

\section{Kesadaran Wajib Pajak}

Rahayu, 2017, 191: menyatakan bahwa kesadaran wajib pajak adalah kondisi dimana wajib Pajak mengerti dan memahami arti, fungsi maupun tujuan pembayaran pajak kepada Negara, dengan kesadaran Wajib Pajak yang tinggi akan memberikan pengaruh kepada meningkatkan kepatuhan pajak yang 
lebih baik lagi.Wardani dan Rumiyatun, 2017, 19: adapun indikator yang mempengaruhi kesadaran wajib pajak yaitu :

1. Kesadaran adanya hak dan kewajiban pajak untuk memenuhi kewajiban membayar pajak

2. Kepercayaan masyarakat dalam membayar pajak untuk pembiayaa negara dan daerah.

3. Dorongan diri sendiri untuk membayar pajak

\section{Sanksi Pajak}

Menurut Mardiasmo , 2013, 62: menyatakan bahwa sanksi pajak merupakan jaminan bahwa ketentuan peraturan perundang-undangan perpajakan (norma perpajakan) akan dituruti/ditaati/dipatuhi, atau perpajakan merupakan alat pencegahan (preventif) agar wajib pajak tidak melanggar norma perpajakan.Wardani dan Rumiyatun, 2017, 20: menyatakan bahwa sanksi pajak dapat diukur dengan indikatorsebagai berikut :

1. wajib pajak mengetahui mengenai tujuan sanksi perpajakan.

2. pengenaan sanksi yang cukup berat merupakan salah satu untuk mendidik wajib pajak

3. sanksi pajak harus dikenaan pada wajib pajak yang melanggar tanpa toleran.

\section{Sistem Samsat Drive Thru}

Wardani dan Rumiyatun, 2017, 20: menyatakan bahwa sistem drive thruadalah sistem dan prosedur pengurusan STNK dengan menggunakan perangkat bantu teknologi informasi, dalam hal ini pengemudi tidak perlu turun dari kendaraannya. pengemudi cukup memberikan data STNK lamanya di loket yang bisa dicapai tanpa perlu keluar mobil. Wardani dan Rumiyatun, 2017, 20: menyatakan bahwa sistem samsat drive thru dapat di ukur dengan indikator sebagi berikut:

1. Samsat Drive Thru dapat lebih Terkontrol dalam hal pendataan kendaraan bermotor.

2. Wajib Pajak dapat dengan mudah membayar Pajak dengan menggunaan Samsat Drive Thru

3. Menghemat waktu

\section{Kepatuhan Wajib Pajak}

Rahayu, 2017, 193: menyatakan bahwa kepatuhan wajib pajak adalah tindakan wajib pajak dalam pemenuhan kewajiban perpajakannya sesuai dengan ketentuan peraturan perundang-undangan dan peraturan pelaksanaan perpajakan yang berlaku dalam suatu negara.Rahayu, 2017, 193: menyatakan bahwa kepatuhan wajib pajak dapat diukur dengan indikator sebagai berikut:

1. Tepat waktu dalam menyetorkan pajak

2. Tepat waktu dalam melaporkan pajak yang sudah dibayar.

3. Tepat dalam menghitung pajak sesuai dengan peraturan undang-undang. 


\section{Metodelogi Penelitian}

Penelitian yang akan dilakukan bersifat kualitatif. Sumber Data yang digunakan dalan penelitian ini adalah data primer data yang diperoleh melalui sumber data yang ada, yaitu data yang diperoleh dari responden melalui kuesioner dan Observasi langsung dengan Wajib Pajak yang terdaftar pada kantor Samsat Bandar Lampung.Kuisioner dilakukan dengan menggunakan skala Likert.Populasi dalam penelitian ini adalah wajib pajak yang terdaftar pada kantor Samsat Bandar Lampung pada tahun 2017 sebanyak 394.604 wajib pajak. Sampel yang digunkaan dalam penelitian iniadalah 100 wajib pajak kendaraan bermotor yang terdaftar pada Kantor Samsat Bandar Lampung yang diperoleh dari hasil rumus Slovin:

$$
\begin{aligned}
& \mathrm{n}=\frac{\mathrm{N}}{1+\left(\mathrm{N} \mathrm{x} \mathrm{e}^{2}\right)} \\
& \mathrm{n}=\frac{394.604}{1+\left(394.604 \times 0,1^{2}\right)} \\
& \mathrm{n}=\frac{394.604}{1+(394.604 \times(0,01)} \\
& \mathrm{n}=\frac{394.604}{1+3.946} \\
& \mathrm{n}=\frac{394.604}{3.946} \\
& \mathrm{n}=100 \text { orang }
\end{aligned}
$$

\section{Hasil dan Pembahasan Uji Validasi dan Reliabilitas}

Hasil perhitungan menunjukkan bahwa semua item dapat dikatakan valid, karena hasil pengelolaan data di dapat bahwa nilai Corrected item-total correlation untuk masing-masing item $>0.165$, maka dapat dinyatakan bahwa semua item pernyataan masing-masing variabel dinyatakan sudah valid dan secara Reliabilitas menunjukkan bahwa hasil pengelolaan data di dapat bahwa nilai Cronbach's Alphauntuk masing-masing item >0,60, maka dapat dinyatakan bahwa semua item pernyataan masing-masing variabel dinyatakan sudah reliable

\section{Uji Asumsi Klasik}

\section{Uji Nomalitas}

Uji normalitas bertujuan untuk menguji apakah dalam model regresi variabel pengganggu atau residual memiliki distribusi normal 
Tabel 2 Hasil Uji Normalitas

One-Sample Kolmogorov-Smirnov Test

\begin{tabular}{|c|c|c|}
\hline & & $\begin{array}{c}\text { UNSTANDARDIZED } \\
\text { RESIDUAL }\end{array}$ \\
\hline $\begin{array}{l}\mathrm{N} \\
\text { Normal Parameters }{ }^{\mathrm{a}, \mathrm{b}}\end{array}$ & $\begin{array}{l}\text { Mean Std. } \\
\text { Deviation }\end{array}$ & $\begin{array}{r}100 \\
, 0000000 \\
1,40198004\end{array}$ \\
\hline Most Extreme Differences & $\begin{array}{l}\text { Absolute } \\
\text { Positive } \\
\end{array}$ & $\begin{array}{l}, 060 \\
, 060 \\
\end{array}$ \\
\hline $\begin{array}{l}\text { Test Statistic } \\
\text { Asymp. Sig. (2-tailed) }\end{array}$ & Negative & $\begin{array}{r}-, 055 \\
, 060 \\
, 200^{\mathrm{c}, \mathrm{d}} \\
\end{array}$ \\
\hline
\end{tabular}

Sumber: Data diolah SPSS 22 (2020)

Berdasarkan tabel 3diatas menunjukkan bahwa hasil pengelolaan data berdistribusi normal, dikatakan normal karena tingkat signifikannya $0,200>0,05$

\section{Uji Heteroskedastisitas}

Berdasarkan hasil pengelolaan data di dapat bahwa titik-titik data menyebar di atas dan bawah titik 0 (nol) pada sumbu Y dan X, titik-titik tidak mengumpul hanya diatas atau dibawah saja serta tidak membentuk pola tertentu maka dapat disimpulkan bahwa dalam penelitian ini tidak terjadi gejala heteroskedastisitas.

\section{Uji multikolinearitas}

Berdasarkan hasil pengelolaan data menunjukkan bahwa tidak terjadi gejala multikolonearitas pada hasil pengelolaan data di dapat nilaiVariance Inflation Factorkesadaran wajib pajak, sanksi pajak dan sistem samsat drive thru kurang dari 10,00 dan nilai tolerance lebih besar dari 0,1 maka dapat disimpulkan tidak terjadi multikolinearitas.

\section{Uji Autokolerasi}

Berdasarkan hasil pengeloaan data model Summary didaptkan hasil Durbin - Watson pada pengujian ini sebesar 1,534, sedangkan dari tabel DurbinWatson dengan signifikan 0,05 dan jumlah $n=100$ serta $K=3$ (jumlah variabel independen) diperoleh nilai dL sebesar 1.6131 dan nilai dU 1.7364 dan nilai 4dU sebesar 2.3869, nilai 4-dL sebesar 2.2636. Karena nilai Durbin- Watson 1.534 yang terletak diantara $\mathrm{d}>4-\mathrm{dL}$

$(2.3869>2.2636)$, maka model regresi terjadi autokorelasi negative.

\section{Uji Regresi Linier Berganda}


Tabel 3:

Hasil Uji Regresi Linier Berganda

Coefficients $^{\mathrm{a}}$

\begin{tabular}{|c|c|c|c|c|c|c|}
\hline \multirow{2}{*}{\multicolumn{2}{|c|}{ Model }} & \multicolumn{2}{|c|}{$\begin{array}{l}\text { Unstandardized } \\
\text { Coefficients }\end{array}$} & \multirow{2}{*}{$\begin{array}{c}\begin{array}{c}\text { Standard } \\
\text { ized } \\
\text { Coefficie } \\
\text { nts }\end{array} \\
\text { Beta }\end{array}$} & \multirow[b]{2}{*}{$t$} & \multirow[b]{2}{*}{ Sig. } \\
\hline & & B & Std. Error & & & \\
\hline \multirow[t]{4}{*}{1} & (Constant) & 2.174 & 1.058 & & 2.054 & .043 \\
\hline & $\begin{array}{l}\text { Kesadaran } \\
\text { Wajib Pajak }\end{array}$ & -.049 & .114 & -.041 & -.430 & .668 \\
\hline & Sanksi Pajak & .654 & .094 & .643 & 6.968 & .000 \\
\hline & $\begin{array}{l}\text { Sistem Samsat } \\
\text { Drive Thru }\end{array}$ & .243 & .093 & .214 & 2.610 & .010 \\
\hline
\end{tabular}

Sumber : Data Diolah SPSS 22 (2020)

Berdasarkan tabel 4hasil perhitungan di atas diperoleh model persamaan regresi berikut: $Y=\alpha+b_{1} X_{1}+b_{2} X_{2}+b_{3} X_{3}+e$

$\mathrm{Y}=2.174-0,049 \mathrm{X}_{1}+0,654 \mathrm{X}_{2}+0,243 \mathrm{X}_{3}+\mathrm{e}$

Dari persamaan diatas diperoleh, maka dapat dijelaskan sebagai berikut:

1. Nilai konstanta $\alpha$ sebesar 2.174 artinya bahwa apabila variabel X1 (kesadaran wajib pajak), X2 (sanksi pajak) dan X3(sistem samsat drive thru) dianggap bernilai tetap maka nilai Y (kepatuhan wajib pajak) sebesar 2.174

2. Koefisien regresi X1 (kesadaran wajib pajak) bernilai negatif sebesar -0,049 hal ini berarti jika nilai lainnya tetap, dan kesadaran wajib pajak mengalami kenaikan 1 (satuan), maka kepatuhan wajib pajak akan mengalami penurunan sebesar 0,049 atau 049\%. Koefisien bernilai negative artinya terjadi hubungan negative antara kesadaran wajib pajak dengan kepatuhan wajib pajak

3. Koefisien regresi X2 (sanksi pajak) bernilai positif sebesar 0,654 hal ini berarti jika nilai lainnya tetap dan sanksi pajak mengalami kenaikan 1 (satuan), maka kepatuhan wajib pajak akanmengalami kenaikan sebesar 0,654 atau 65,4\% . Koefisien bernilai positif artinya sanksipajak memeberi pengaruh positif. Semakin tinggi sanksi pajak maka semakin tinggi juga kepatuhan wajib pajak

4. Koefisien regresi X3 (sistem samsat drive thru) bernilai positif sebesar 0,243 hal ini berarti jika nilai lainnya tetap dan sistem samsat drive thrumengalami kenaikan 1 (satuan), maka kepatuhan wajib pajak akan mengalami kenaikan 0,243 atau 24,3\%. Koefisien bernilai positif artinya sistem samsat drive thru memberi pengaruh positif. Semakin tinggi sistem samsat drive thru maka semakin tinggi juga kepatuhan wajib pajak 


\section{Uji Koefisien Determinasi (R2)}

Tabel 4:

Hasil Uji Koefisien Determinasi (R2)

Model Summary ${ }^{\mathrm{b}}$

\begin{tabular}{|l|r|r|r|r|r|}
\hline $\begin{array}{l}\text { Mode } \\
1\end{array}$ & $\mathrm{R}$ & $\mathrm{R}$ Square & $\begin{array}{c}\text { Adjusted R } \\
\text { Square }\end{array}$ & $\begin{array}{c}\text { Std. Error of } \\
\text { the Estimate }\end{array}$ & $\begin{array}{c}\text { Durbin- } \\
\text { Watson }\end{array}$ \\
\hline 1 & $.743^{\mathrm{a}}$ & .552 & .538 & 1.424 & 1.534 \\
\hline
\end{tabular}

a. Predictors: (Constant), Sistem Samsat Drive Thru, Sanksi Pajak, Kesadaran Wajib Pajak

b. Dependent Variable: Kepatuhan Wajib Pajak

Sumber: Data Diolah SPSS 22 (2020)

Berdasarkan hasil analisi diperoleh nilai $\mathrm{R}$ Square sebesar 0,552. Dengan demikian menunjukan bahwa kesadaran wajib pajak, sanksi pajak dan sistem samsat drive thru secara bersama-sama mempengaruhi kepatuhan wajib pajak sebesar 55,2\% dan sisanya yaitu 44,8\% dipengaruhi oleh faktor lainnya yang tidak dikaji dalam penelitian ini.

Uji Simultan (F)

Tabel 5:

Hasil Uji Simultan (F)

ANOVA $^{\mathrm{a}}$

\begin{tabular}{|c|c|c|c|c|c|c|}
\hline \multicolumn{2}{|c|}{ Model } & $\begin{array}{l}\text { Sum of } \\
\text { Squares }\end{array}$ & $\mathrm{df}$ & $\begin{array}{l}\text { Mean } \\
\text { Square }\end{array}$ & $\mathrm{F}$ & Sig. \\
\hline \multirow[t]{3}{*}{1} & Regression & 240.161 & 3 & 80.054 & 39.494 & $.000^{\mathrm{b}}$ \\
\hline & Residual & 194.589 & 96 & 2.027 & & \\
\hline & Total & 434.750 & 99 & & & \\
\hline
\end{tabular}

a. Dependent Variable: Kepatuhan Wajib Pajak

b. Predictors: (Constant), Sistem Samsat Drive Thru, Sanksi Pajak, Kesadaran Wajib Pajak

Sumber: Data Diolah SPSS 22 (2020)

Berdasarkan tabel 5 hasil perhitungan diatas bisa dilihat $\mathrm{F}$ mendapat nilai $t_{\text {thitung }}$ sebesar 39.494 dan $t$ tabel sebesar 2.70. Hal ini menunjukkan bahwa thitung $>$ tabel artinya variabel $\mathrm{X}$ secara parsial berpengaruh terhadap variabel $\mathrm{Y}$ dengan nilai signifikan 0,000 yaitu lebih kecil dari 0,05 . Hal ini mengartikan $39.494 \mathrm{t}$ hitung $>\mathrm{t}$ tabel 2.70 dengan nilai sig $\leq 0,05$ maka Ha diterima dan dapat disimpulkan bahwa kesadaran wajib pajak, sanksi pajak dan sistem samsat drive thruberpengaruh positif dan signifikan terhadap kepatuhan wajib pajak dalam membayar pajak kendaraan bermotor. 


\section{Uji Parsial}

\section{Coefficients $^{\mathrm{a}}$}

\begin{tabular}{|c|c|c|c|c|c|c|}
\hline \multirow{2}{*}{\multicolumn{2}{|c|}{ Model }} & \multicolumn{2}{|c|}{$\begin{array}{c}\text { Unstandardized } \\
\text { Coefficients }\end{array}$} & \multirow{2}{*}{$\begin{array}{c}\begin{array}{c}\text { Standardized } \\
\text { Coefficients }\end{array} \\
\text { Beta } \\
\end{array}$} & \multirow[b]{2}{*}{$\mathrm{t}$} & \multirow[b]{2}{*}{ Sig. } \\
\hline & & B & Std. Error & & & \\
\hline \multirow[t]{4}{*}{1} & (Constant) & 2.174 & 1.058 & & 2.054 & .043 \\
\hline & $\begin{array}{l}\text { Kesadaran } \\
\text { Wajib Pajak }\end{array}$ & -.049 & .114 & -.041 & -.430 & .668 \\
\hline & Sanksi Pajak & .654 & .094 & .643 & 6.968 & .000 \\
\hline & $\begin{array}{l}\text { Sistem Samsat } \\
\text { Drive Thru }\end{array}$ & .243 & .083 & ber: Data Bio & h ș9ss & $2(202$ \\
\hline
\end{tabular}

Berdasarkan hasil uji t diatas diperoleh :

1. Pengaruh kesadaran wajib pajak terhadap kepatuhan wajib pajak.

Hipotesis kedua, kesadaran wajib pajak $\left(\mathrm{X}_{1}\right)$ secara parsial tidak bepengaruh positif dan signifikan terhadap kepatuhan wajib pajak $(\mathrm{Y})$. Kesadaran wajib pajak $\left(\mathrm{X}_{1}\right)$ mendapat nilai thitung- $0,430<\mathrm{t}$ tabel 1,66023 dengan tingkat signifikan 0,668>0,dapat disimpulkan bahwa kesadaran wajib pajak tidak berpengaruh positif dan signifikan terhadap kepatuhan wajib pajak dalam membayar pajak kendaraan bermotor pada Kantor Samsat Bandar Lampung.

2. Pengaruh sanksi pajak $\left(\mathrm{X}_{2}\right)$ terhadap kepatuhan wajib pajak $(\mathrm{Y})$ Hipotesis ketiga, sanksi pajak $\left(\mathrm{X}_{2}\right)$ secara parsial bepengaruh positif dan signifikan terhadap kepatuhan wajib pajak $(Y)$. Sanksi pajak $\left(\mathrm{X}_{2}\right)$ mendapat nilai thitung $6.968>\mathrm{t}$ tabel sebesar 1,66023 dengan tingkat signifikan $0,000<0$, maka dapat disimpulkan bahwa sanksi pajak berpengaruh positif dan signifikan terhadap kepatuhan wajib pajak dalam membayar pajak kendaraan bermotor pada Kantor

Samsat Bandar Lampung

3. Pengaruh sistem samsat drive thru terhadap kepatuhan wajib pajak Hipotesis keempat, Sistem samsat drive thru $\left(\mathrm{X}_{3}\right)$ secara parsialberpengaruh positif dan signifikan terhadap kepatuhan wajib pajak. Sistem samsat drive thru mendapat nilai thitung 2,610> $\mathrm{t}_{\text {tabel }}$ 1,66023 dengan tingkat signifikan $0,010<0,05$, maka dapat disimpulkan bahwa sistem samsat drive thru berpengaruh positif dan signifikan terhadap kepatuhan wajib pajak dalam membayar pajak kendaraan bermotor pada Kantor Samsat Bandar Lampung.

\section{Pengaruh kesadaran wajib pajak terhadap kepatuhan wajib pajak}

Berdasarkan hasil perhitungan variabel kesadaran wajib pajak $\left(\mathrm{X}_{1}\right)$ secara parsial tidak berpengaruh positif dan signifikan terhadap kepatuhan wajib pajak, dimana perhitungan tersebut memperoleh nilai thitung $-0,430$ dan $t$ tabel 1,66023 maka $t_{\text {hitung }}<\mathrm{t}_{\text {tabel }}$ dengan nilai sig 0,668 > 0,05, maka H2 ditolak dan dapat disimpulkan bahwa kesadaran wajib pajak tidak berpengaruh dan 
signifikan terhadap kepatuhan wajib pajak dalam membayar pajak kendaraan bermotor.

Dapat diketahui bahwa variabel kesadaran wajib pajak tidak mempunyai pengaruh yang signifikan terhadap kepatuhan wajib pajak, yang dibuktikan dari uji analisi regresi linier berganda. Bentuk tidak berpengaruh dari kesadaran wajib pajak terhadap kepatuhan wajib pajak tersebut dapat digambarkan dengan persamaan regresi linier berganda yang diperoleh nilai koefisien regresi yang bertanda negative yaitu hal tersebut menunjukkan bahwa sanksi kesadaran wajib pajak tidak mempunyai pengaruh yang positif terhadap kepatuhan wajib pajak.

Kesadaran wajib pajak merupakan sikap baik seseorang untuk memenuhi kewajibannya dalam memabayar pajak dengan tulus dan ikhlas dan menyadari bahwa itu merupakan kewajiban yang harus dipenuhinya. Apabilah wajib pajak sudah melaksanakan kewajibannya dan menyadari betapa pentingnya pajak untuk pembangunan daerahnya, maka tidak akan terjadi namanya ketidakpatuhan dalam membayar pajak.Hal ini sesuai dengan pendapat Rahayu, 2017, 191: menyatakan bahwa kesadaran Wajib pajak adalah kondisi dimana wajib Pajak mengerti dan memahami arti, fungsi maupun tujuan pembayaran pajak kepada Negara.

\section{Pengaruh sanksi pajak terhadap kepatuhan wajib pajak}

Berdasarkanhasil perhitunga variabel sanksi pajak $\left(\mathrm{X}_{2}\right)$ secara parsial berpengaruh positif dan signifikan terhadap kepatuhan wajib pajak ,dimana perhitungan tersebut memperoleh nilai thitung $6.968>\mathrm{t}$ tabel 1,66023 dengan nilai sig $0,000 \leq 0,05$ maka Ha diterima dan dapat disimpulkan bahwa sanksi pajak berpengaruh positif dan signifikan terhadap kepatuhan wajib pajak dalam membayar pajak kendaraan bermotor. Dari hasil penelitian ini dapat diketahui bahwa sanksi pajak terhadap kepatuhan wajib pajak termasuk dalam kategori baik sesuai dengan pernyataan sebagian besar responden.

Hasil penelitian ini sejalan dengan Penelitian yang dilakukan Yanti, 2015, yang berjudul " pengaruh kualitas pelayanan, sanksi pajak dan kondisi keuangan wajib pajak terhadap kepatuhan wajib pajak kendaraan bermotor" hasil dari penelitiannya menunjukkan bahwa sanksi pajak secara parsial berpengaruh positif dan signifikan terhadap kepatuhan wajib pajak kendaraan bermotor.

\section{Pengaruh sistem samsat drive thru terhadap kepatuhan wajib pajak}

Berdasarkan tabel 4.9 secara parsial sistem samsat drive thru (X3)berpengaruhterhadap kepatuhan wajib pajakdengan $\mathrm{X}_{3}$ mendapat nilai $t_{\text {hitung } 2,610>t}$ tabel 1,66023 dengan nilai sig $\leq 0,05$ maka Ha diterima dan dapat disimpulkan bahwa sistem samsat drive thru berpengaruh positif dan signifikan terhadap kepatuhan wajib pajak dalam membayar pajak kendaraan bermotor.

Hasil penelitian ini sejalan dengan hasil penelitian yang dilakukan olehWardani dan Rumiyatun, 2017 yang berjudul "pengaruh pengetahuan 
wajib pajak, kesadaran wajib pajak, sanksi pajak kendaraan bermotor, dan sistem samsat drive thru terhadap kepatuhan wajib pajak kendaraan bermotor" hasil dari penelitiannya menunjukkan bahwa sistem samsat drive thru secara parsial berpengaruh positif dan signifikan terhadap kepatuhan wajib pajak.

\section{Pengaruh kesadaran wajib pajak, sanksi pajak, dan sistem samsat drive thru terhadap kepatuhan wajib pajak}

Berdasarkan hasil perhitungan didapatkan kesadaran wajib pajak, sanksi pajak dan system drive thru secara simultan berpengaruh positif dan signifikan terhadap kepatuhan wajib pajak, perhitungan tersebut memperoleh nilai $f_{\text {hitung }}$ $39.494>f_{\text {tabel }} 2.70$ dengan nilai sig $0.000 \leq 0,05$ yang berarti kesadaran wajib pajak, sanksi pajak dan sistem samsat drive thru secara simultan berpengaruh positif dan signifikan terhadap kepatuhan wajib pajak dalam membayar pajak kendaraan bermotor.

Penelitian ini sejalan dengan penelitian yang dilakukan Ummah, 2015, yang berjudul " pengaruh kesadaran wajib pajak, sanksi pajak, pengetahuan pajak, dan pelayanan fiskus terhadap kepatuhan wajib pajak kendaraan bermotor di Kabupaten Semarang" hasil dari penelitiannya menunjukkan bahwa kesadaran wajib pajak, sanksi pajak, pengetahuan pajak dan pelayanan secara simultan berpengaruh positif dan signifikan terhadap kepatuhan wajib pajak.

Oleh karena itu, untuk menjamin kepatuhan wajib pajak, salah satu upaya yang harus dilakukan oleh Kantor Samsat Bandar lampung yaitu dengan meningkatkan kesadaran wajib pajak dengan cara sosialisasi maupun cara lainnya, semakin tinggi sanksi pajak yang diberikan maka akan meningkatkan kepatuhan wajib pajak dan sistem samsat drive thru harus terus berjalan dengan baik, agar kepatuahn wajib pajak semakin meningkat.

\section{Kesimpulan}

1. Kesadaran wajib pajak secara parsial tidak berpengaruh postif dan signifikan terhadap kepatuhan wajib pajak dalam membayar pajak kendaraan bermotor pada Kantor Samsat Bandar lampung. Hal ini menunjukkan bahwa perlu adanya peningkatan kesadaran wajib pajak pada Kantor Samsat Bandar Lampung.

2. Sanksi pajak secara parsial berpengaruh positif dan signifikan terhadap kepatuhan wajib pajak dalam membayar pajak kendaraan bermotor pada Kantor Samsat Bandar Lampung. Hal ini menunjukkan bahwa semakin tinggi sanksi pajak pada Kantor Samsat Bandar Lampung, maka semakin tinggi pula tingkat kepatuhan wajib pajak kendaraan bermotor.

3. Sistem Samsat Drive Thru secara parsial berpengaruh positif dan signifikan terhadap kepatuhan wajib pajak dalam membayar pajak kendaraan bermotor pada kantor Samsat Bandar Lampung. Hal ini menunjukkan bahwa semakin tinggi sistem samsat drive thru pada Kantor Samsat Bandar Lampung, maka semakin tinggi pula tingkat kepatuhan wajib pajak kendaraan bermotor. 
4. Kesadaran wajib pajak, sanksi pajak, dan sistem samsat drive thru secara simultan berpengaruh positif terhadap kepatuhan wajib pajak dalam membayar pajak kendaraan bermotor pada kantor samsat Bandar lampung. Hal ini menunjukkan bahwa semakin tinggi kesadaran wajib pajak, sanksi pajak dan sistem samsat drive thru pada Kantor Samsat Bandar Lampung, maka semakin tinggi pula tingkat kepatuhan wajib pajak kendaraan bermotor.

\section{Saran}

1. Kesadaran wajib pajak perlu ditingkatkan lagi dalam diri wajib pajak. Kesadaran akan pentingnya pajak dalam pembangunan Negara terutama pembangunan daerah, salah satu upaya yang harus dilakukan oleh Kantor Samsat Bandar Lampung adalah melakukan Sosialisasi agar dapat menambah jumlah kepatuhan wajib pajak. Sosialisasi mengenai undangundang perpajakan, tujuan serta fungsi pajak agar dapat meningkatkan kepatuhan wajib pajak.

2. Sanksi pajak dengan adanya sanksi pajak maka kepatuhan wajib pajak menjadi meningkat. Oleh karena itu, untuk menjamin kepatuhan wajib pajak, salah satu upaya yang harus dilakukan oleh Kantor Samsat Bandar lampung yaitu dengan menjaga agar sanski pajak terus berjalan dengan baik, agar kepatuahn wajib pajak semakin meningkat jika kepatuhan wajib pajak semakin meningkat maka akan menambah Pendapatan Asli Daerah.

3. Sistem samsat drive thru dengan adanya kepatuhan wajib pajak maka kepatuhan wajib pajak menjadi meningkat. Oleh karena itu, untuk menjamin kepatuhan wajib pajak Kantor Samsat Bandar Lampung harus meningkatkan lagi kualitas dari sistem samasat drive thru dengan kualitas yang lebih baik maka kepatuhan wajib pajak akan semakin meningkat dan akan menambah Pendapatan Asli Daerah.

4. Penelitian ini hanya mengambil populasi pada Kantor Samsat Bandar lampung dan objek penelitaian pada wajib pajak yang membayar pajak kendaraan bermotor. Oleh karena itu, diharapkan pada penelitian selanjutnya dapat melakukan ruang lingkup penelitian yang lebih luas lagi, sehingga dapat memperoleh hasil yang lebih tepat.

\section{Daftar Pustaka}

Ghozali, Imam. 2013. Aplikasi analisis Multivariate dengan Program IBM SPSS 21

Update PLS Regresi. Semarang: Badan Penerbit Universitas Diponogoro.

Halim, Abdul. 2017. Perpajakan konsep aplikasi, contoh, dan studi kasus. Semarang: Salemba Empat.

Mardiasmo. 2013. Perpajakan Edisi Revisi.Yogyakarta: Andi Offset.

Mardiasmo. 2016. Perpajakan.Yogyakarta:Andi Offset.

Rahayu, Suti Kurnia. 2017. Perpajakan Knsep Dan Aspek Formal. Bandung: Rekayasa Sains.

Sambodo, Agus. 2015. Pajak dalam Entitas Bisnis.Jakarta: Salemba Empat. 
Sanusi, Anwar. 2016. Metodelogi Penelitian Bisnis. Jakarta: Salemba Empat.

Sarwono,Jonathan dan Salim, Hendra Nur. 2016. Analisis Data Riset Skripsi.Yogyakarta: Gava Media.

Siregar, Sofyan. 2015. Statistik Terapan. Jakarta: Kencana.

Sujarweni, V Wiratna. 2014. Metodelogi Penelitian.Yogyakarta: Pustaka Baru Press.

Ummah, Muslikhatul. 2015, Pengaruh kesadaran wajib pajak, sanksi pajak, pengetahuan perpajakan dan pelayanan fiskus terhadap kepatuhan wajib pajak kendaraan bermotor di Kabupaten Semarang. Semarang: Fakultas Ekonomi Universitas Dian Nuswantoro.

Waluyo. 2015. Perpajakan Indonesia Edisi 10. Jakarta: Salemba Empat.

Wardani, Dewi Kususma dan Rumiyatun. 2017. Pengaruh pengetahuan wajib pajak, kesadaran wajib pajak, sanksi pajak kendaraan bermotor, dan sistem Samsat Drive Thru terhadap Kepatuhan Wajib Pajak Kendaraan Bermotor. Yogyakarta: Universitas Sarjawawijayata Tamansiswa Yogyakarta

Yanti, Widia Dwi Ratna. 2015. Pengaruh kualitas pelayanan, sanksi pajak, dan kondisi keuangan wajib pajak terhadap kepatuhan wajib pajak. Surabaya: Universitas Negeri Surabaya. 